\title{
Analysis of Single Nucleotide Polymorphism A118g Gene Opioid Receptor Mu-1 (OPRM1) In Opioid Analgesic Patients in Indonesia
}

\author{
Mara Imam Taufiq Siregar, Arie Utariani*, Hamzah, Elizeus Hanindito, \\ Prananda Surya Airlangga and Retno Handajani
}

\author{
Department Clinical Medicine, Faculty of Medicine, Universitas Airlangga Surabaya \\ Indonesia 60286
}

*Corresponding author details: Arie Utariani; utarianiarie@gmail.com

\begin{abstract}
Introduction: Opioid Receptor Mu-1 or Opioid Receptor Mu-1 (OPRM1) is a prime candidate for pharmacogenetic studies related to the variability of patient response to opioids. This variant is high frequency in Asian populations that is associated with differences in sensitivity and increased need for opioid analgesics in the treatment of pain. Therefore, this study was conducted with the aim of analyzing OPRM1 in patients receiving opioid analgesics in Indonesia, especially in the city of Surabaya.

Method: The method used is the Polymerase Chain Reaction-Restriction Fragment Length Polymorphism (PCR-RFLP), where the data collected is recorded and tabulated and then analyzed using SPSS version 20.0.

Result: The results showed that the frequency of SNP A118G of the OPRM1 gene was found to be quite high, namely $58(72.5 \%)$ out of a total of 80 subjects. In 40 male subjects, the GG genotype frequency was found to be the highest at 19 (47.5\%). While the genotype frequencies of AA, AG and GG were found to be almost comparable in women.

Conclusion: Therefore, it can be concluded that the frequency of SNP A118G of the OPRM1 gene was found to be high in the Indonesian population and had a high tendency in the male population, although it was not statistically significant.
\end{abstract}

Keywords: OPRMI gene; SNP A118G; opioid receptors; Male and Female; PCR-RFLP

\section{INTRODUCTION}

Opioids are the main analgesia used for the treatment of moderate to severe pain in patients. The analgesic efficacy of opioids such as fentanyl and morphine are known to vary widely. Therefore, the incidence of pain experienced is very different. This makes it difficult to predict optimal pain management in each patient (López Soto et al., 2013) (Boules et al., 2015) (Taqi et al., 2019). For this reason, it is important to analyze the mechanisms responsible for this inter-individual variation. Various non-genetic factors have an impact on the patient's pain sensitivity such as: age, gender, anxiety, liver and kidney function, type of surgery and preoperative pain. Advances in genetic research indicate that genetic polymorphisms contribute to patient variability in response to opioid treatment (Taqi et al., 2019) (Puspitasari et al., 2020).

Genetic and psychological variations are increasingly being recognized as contributing to pain relief, analgesic efficacy and safety. Differences in analgesic efficacy related to body composition, metabolism, and hormonal profile have been demonstrated. Gender psychological and social elements have also been associated with altered pain experience and analgesic use profiles, although with significant individual variation. Experimentally, in men with neuropathic pain, macrophages are the most active immune cells. In women, neuropeptides, which are protein-like substances, are more prominently released by neurons.
The mu-1 opioid receptor, encoded by the Opioid Receptor Mu-1 (OPRM1) gene, is a prime candidate for pharmacogenetic studies of patient response variability to opioids because it is the primary site of action for many endogenous opioid peptides including -endorphins and enkephalins, as well as their target The main drugs for opioid analgesics are fentanyl and morphine. A number of single nucleotide polymorphisms (SNPs), otherwise known as single nucleotide polymorphisms, have been found in the OPRM1 gene (Kasai \& Ikeda, 2011) (López Soto et al., 2013) (Hwang et al., 2016) (Boules et al., 2015) (Taqi et al., 2019) (Puspitasari et al., 2020).

This substitution is thought to lead to the loss of the Nglycosylation site in the extracellular region of the receptor. Several studies evaluating the effect of SNP $118 \mathrm{~A}>\mathrm{G}$ on the exogenous opioid-induced intracellular signaling cascade (DAMGO and morphine) at the mu- 1 opioid receptor demonstrated a two-fold stronger inhibition of $\mathrm{Ca} 2+$ channel current in neurons with the A allele than in those expressing the receptor with the A allele. G. This suggests reduced function of the $G$ allele variant receptor function which may result in reduced effects of opioid drugs (Ikeda et al., 2005) (Pasternak \& Pan, 2013).

The polymerase chain reaction (PCR) discovered by Kary Mullis in 1985 is known to be an effective and sophisticated procedure for amplification of DNA. 
This process is similar to the process of DNA replication in cells (Chou \& Hsu, 2021). The result of this DNA segment multiplication causes the duplicated DNA segment to be easily detected because of its high concentration (Boules et al., 2015) (Taqi et al., 2019). Electrophoresis visualization of the PCR amplification of the exon 1 gene fragment OPRM1 with forward and reverse primers will appear in the 193 base pairs (bp) band (Udayakumar \& Udayakumar, 2021).

Through this, it can be seen that the A118G SNP exon 1 of the OPRM1 gene has an impact on the variability of the amount of opioid analgesic consumption and is useful in predicting individual selectivity to opioids to optimize patient pain control and to avoid side effects(Kasai \& Ikeda, 2011) (López Soto et al., 2013) (Hwang et al., 2016) (Boules et al., 2015) (Taqi et al., 2019) (Puspitasari et al., 2020). Since the Asian population is the largest for the incidence of SNP A118G gene OPRM1, this study was structured with the aim of analyzing OPRM1 in patients receiving opioid analgesics in Indonesia, especially in the city of Surabaya.

\section{METHOD}

This study is an unpaired categorical comparative analytical study with a cross sectional design (risk factors and effects viewed at the same time / snapshot of the population) to analyze differences in genotype and allele frequencies in the A118G SNP of the Opioid Receptor Mu1 gene (OPRM1) with the method PCR-RFLP in patients with opioid analgesics in one hospital in Indonesia, namely RSUD Dr. Soetomo Surabaya.

This research was conducted from October 2020 to March 2021, where sampling was carried out at RSUD Dr. Soetomo Surabaya and laboratory examinations were carried out at the Integrated Laboratory of the Faculty of Medicine, University of North Sumatra (FK-USU).

The subjects in this study were all male and female patients with surgery who received opioid analgesics at RSUD Dr. Soetomo Surabaya Indonesia. Subjects were taken by consecutive random sampling, that is, all subjects who met the inclusion criteria and were not included in the exclusion criteria were sampled in this study.

\section{RESULT}

\section{Demographic Characteristics of Research Subjects}

Subjects with male gender in this study amounted to 40 $(50 \%)$ patients and $40(50 \%)$ female patients. The mean age of men was $43.6 \pm 15.9$, women were $42.0 \pm 14.1$ and the total subject was $42.8 \pm 14.1$. The mean weight of men was $64.2 \pm 9.7$, women was $65.6 \pm 11.4$ and the total subject was $64.9 \pm 10.5$. The mean height of men was $166.6 \pm 4.8$, women were $156.8 \pm 5.5$ and the total subject was $161.7 \pm 7.1$.
The mean body mass index (BMI) for men was $23.0 \pm 3.0$, women were $26.8 \pm 4.1$ and the total subject was $24.91 \pm$ 4.02. The majority of the subjects in this study $(91.25 \%)$ were Javanese. Based on the Physical Status of the American Society of Anesthesiologist (PS ASA) score, $65.0 \%$ of the subjects were obtained with a PS ASA score of 2, consisting of $27.5 \%$ men and $37.5 \%$ women, the rest of the subjects were obtained with a PS ASA score of 1 and 3.

As many as $50 \%$ of patients underwent orthopedic surgery which consisted of surgery for long bones of the extremities and vertebrae. Subjects who underwent neurosurgery surgery were $6.25 \%$ who were all men with vertebral spine surgery. Subjects who underwent digestive surgery were $3.75 \%$ of patients (all men), consisting of open cholecystectomy and gastrectomy operations. Subjects who underwent plastic surgery were $6.25 \%$ ( $5.0 \%$ men and $1.25 \%$ women), consisting of burn surgery and facial bone reconstruction. Subjects who underwent general surgery were $6.25 \%$ (3.75\% men and $2.5 \%)$, consisting of debridement, necrotomies, skin grafts and amputation of diabetic feet. Subjects who underwent urological surgery, namely TUR-P were $1.25 \%$ with male gender. Subjects who underwent Ear Nose Throat (ENT) surgery, namely FESS, were also $1.25 \%$ male. The last subject was $25 \%$ of female patients who underwent obstetric surgery, namely $\mathrm{TAH}$.

\section{Electrophoresis Results of PCR Products and PCR- RFLP Products Research Subjects}

PCR, RFLP and electrophoresis analysis have been carried out on a total of 80 blood samples of the subjects of this study. From the results of electrophoresis of PCR products, $193 \mathrm{bp}$ fragments were obtained in the visualization process. Furthermore, RFLP and electrophoresis were performed on all subjects' PCR products and $193 \mathrm{bp}$ fragments were obtained in $22(27.50 \%)$ research subjects, namely lane numbers $1,5,7,13,23,24,31,37,40$, $41,44,46,48,50,51,52,53,61,68,75,79$ and 80 which indicate the subject has an AA genotype. In 27 (33.75\%) research subjects, namely lane numbers $2,3,4,16,18,28$, $29,30,33,34,35,36,47,54,55,56,58,59,60,63,64,65$, $66,67,72,73$ and 74 fragments of 193 and 169 bp were obtained, indicating that the subject had the AG genotype. Meanwhile, $31(38.75 \%)$ research subjects, namely lane numbers $6,8,9,10,11,12,14,15,17,19,20,21,22,25,26$, $27,32,38,40,42,43,45,49,57,62,69,70,71,76,77$ and 78 fragments of $169 \mathrm{bp}$ were obtained which indicated that the subject had a GG genotype.

\section{Allele frequency distribution on SNP A118G gene OPRM1 all research subjects}

The distribution of allele frequencies in the A118G SNP of the OPRM1 gene for all research subjects can be seen in table 1.

TABLE 1: The distribution of allele frequencies in the A118G SNP of the OPRM1 gene for all research subjects

\begin{tabular}{|c|c|c|c|c|}
\hline Allele Distribution & $\begin{array}{c}\text { Homozygote AA } \\
\text { N (\%) }\end{array}$ & $\begin{array}{c}\text { Heterozygote AG } \\
\text { N (\%) }\end{array}$ & $\begin{array}{c}\text { Homozygote GG } \\
\mathbf{n}(\%)\end{array}$ & $\begin{array}{c}\text { Total } \\
\text { N (\%) }\end{array}$ \\
\hline A & $44(27,5)$ & $27(16,9)$ & $0(0,0)$ & $71(44,4)$ \\
\hline G & $0(0,0)$ & $27(16,9)$ & $62(38,75)$ & $89(55,6)$ \\
\hline Total & $44(27,5)$ & $54(33,75)$ & $62(38,75)$ & $160(100)$ \\
\hline
\end{tabular}


The table describes the frequency of the G allele, which was found to be 89 (55.6\%) more than the A allele 71 (44.4\%) of the 160 alleles in the subjects of this study. The majority of $\mathrm{G}$ alleles are present in GG homozygous subjects, and the majority of A alleles are present in AA homozygous subjects.

Based on the total genotype frequency of the research subjects, the frequency of the AA genotype was 44 (27.5\%), the AG genotype $54(33.75 \%)$ and the GG genotype 62 $(38.75 \%)$, it can be concluded that the frequency of the A118G SNP polymorphism of the OPRM1 gene was found in $72.5 \%$ of subjects, this figure was obtained from the addition of the AG genotype (33.75\%) and the GG genotype (38.75\%).

Distribution of allele frequencies in SNP A118G gene OPRM1 based on gender of research subjects

The frequency distribution of the $\mathrm{A}$ and $\mathrm{G}$ alleles in the A118G SNP of the OPRM1 gene based on the sex of the research subjects is shown in table 2 .

TABLE 2: Distribution of allele frequencies in SNP A118G gene OPRM1 based on gender of research subjects

\begin{tabular}{|c|c|c|c|}
\hline \multirow{2}{*}{ Allele } & \multicolumn{2}{|c|}{ Sex } & \\
\cline { 2 - 4 } & Men & Women & Total \\
\cline { 2 - 4 } & $\mathbf{N}(\%)$ & N (\%) & N (\%) \\
\hline A & $30(37,5)$ & $41(51,2)$ & $71(44,4)$ \\
\hline G & $50(62,5)$ & $39(48,8)$ & $89(55,6)$ \\
\hline Total & $80(100,0)$ & $80(100,0)$ & $16000,0)$ \\
\hline
\end{tabular}

Table 2 shows that in male subjects, the $\mathrm{G}$ allele frequency was greater than the A allele, which was $62.5 \%$. In contrast to male subjects, female subjects found that the frequency of the A allele was greater than that of the G allele, which was $51.2 \%$.
Differences in Genotype Frequency Distribution in SNP A118G Gene OPRM1 based on Gender

The distribution of genotype frequencies in the A118G SNP of the OPRM1 gene based on the sex of the research subjects is shown in table 3 .

TABLE 3: Differences in the genotype frequency distribution of SNP A118G gene OPRM1 based on the sex of the research subjects.

\begin{tabular}{|c|c|c|c|c|}
\hline \multirow{2}{*}{ Genotype } & Men & Women & Total & \multirow{2}{*}{ P-Value } \\
\cline { 2 - 4 } & $\mathbf{N}(\mathbf{\%})$ & $\mathbf{N}(\%)$ & $\mathbf{N}(\%)$ & \\
\hline $\begin{array}{c}\text { Wild type (AA) } \\
\text { Mutan Heterozigot (AG) } \\
\text { Mutan homozigot (GG) } \\
\text { Total }\end{array}$ & $9(22,5)$ & $13(32,5)$ & $22(27,5)$ & \\
\cline { 2 - 4 } & $12(30,0)$ & $15(37,5)$ & $27(33,75)$ & \multirow{2}{*}{$0,267^{*}$} \\
\cline { 2 - 4 } & $19(47,5)$ & $12(30,0)$ & $31(38,75)$ & \\
\cline { 2 - 4 } & $40(100,0)$ & $40(100,0)$ & $80(100,0)$ & \\
\hline HWE ( $\chi 2$ Value) & $\begin{array}{c}0,139 \\
(P>0,05)\end{array}$ & $\begin{array}{c}0,839 \\
(P>0,05)\end{array}$ & $\begin{array}{c}0,466 \\
(P>0,05)\end{array}$ & \\
\hline
\end{tabular}

* Difference is not significant, $p>0.05$

Based on the Chi-square test, it can be concluded that there is no significant difference in the frequency distribution of the SNP A118G genotype of the OPRM1 gene based on the sex of the subject in this study with $p=0.267(p>0.05)$. The frequency distribution of the A118G SNP genotype of the OPRM1 gene in this study, both in men, women and in total subjects, did not have a significant deviation based on the Hardy-Weinberg Equilibrium/HWE (value 2).
Differences in Allele Frequency Distribution in SNP A118G Gene OPRM1 Based on Gender of Research Subjects

The difference in allele frequency distribution in SNP A118G gene OPRM1 based on the sex of the research subjects can be seen in table 4 .

TABLE 4: Differences in allele frequency distribution in SNP A118G gene OPRM1 based on gender of research subjects.

\begin{tabular}{|c|c|c|c|c|c|}
\hline \multirow{2}{*}{ Allele } & Men & Women & Total & $\begin{array}{c}\text { P-Value } \\
\text { (Chi-Square) }\end{array}$ & \multirow{2}{*}{ OR $^{\mathbf{1}}$} \\
\cline { 2 - 4 } & $\mathbf{N ~ ( \% )}$ & $\mathbf{N}(\mathbf{\%})$ & $\mathbf{N}(\%)$ & $71(44.4)$ & \\
\hline A & $30(37.5)$ & $41(51.2)$ & \multirow{2}{*}{$0.08^{*}$} & 0,571 \\
\hline G & $50(62.5)$ & $39(48.8)$ & $89(55.6)$ & & \\
\hline Total & $80(100)$ & $80(100)$ & $160(100)$ & & \\
\hline
\end{tabular}

* Difference is not significant, $p>0.05$ 
Based on the Chi-square test conducted, it can be concluded that there is no significant difference in the distribution of the SNP A118G allele frequency of the OPRM1 gene based on the sex of the research subjects, with $p$ value $=0.08(p>0.05)$. Given the $p$ value $>0.05$, the $O R$ value in this study cannot be used as a recommendation to conclude which sex is more at risk of having the $A$ or $G$ allele in the A118G SNP of the OPRM1 gene.

\section{DISCUSSION}

Through the results of the study, it was found that the frequency of the wild type (AA) genotype was at $27.5 \%$. Then genotype heterozygous mutant (AG) in $33.75 \%$ and homozygous mutant genotype (GG) in $38.75 \%$ of the total 80 subjects.

In this study, $72.5 \%$ of subjects had at least $1 \mathrm{G}$ allele in their genotype, namely the mutant heterozygous (AG) and homozygous mutant (GG) genotypes]. This condition is in accordance with the research of Puspitasari et al. (2020) who got $82.2 \%$ or have at least $1 \mathrm{G}$ allele in their genotype. These two studies illustrate the high frequency of the $G$ allele in the Indonesian population, which reaches more than $70 \%$ of the population.

Another study conducted by Zahari et al. (2018) in Malaysia, found the frequency of wild type (AA) genotypes in $23.0 \%$ of subjects. Then there is a heterozygous mutant genotype (AG) in $47.8 \%$ and a homozygous mutant genotype (GG) in $29.2 \%$ of a total of 161 subjects. This study is in line with the study of Zahari et al. (2018) who also found a high number of subjects with at least $1 \mathrm{G}$ allele in their genotype, namely $77.0 \%$.

\section{Allele Frequency Distribution of SNP A118G Gene OPRM1 in Research Subjects}

This study found that the SNP frequency of $118 \mathrm{~A}$ allele was $44.4 \%$ and $118 \mathrm{G}$ allele was $55.6 \%$ from 160 alleles in a total of 80 subjects. This certainly further confirms the high frequency of the G SNP A118G allele of the OPRM1 gene in the population in Indonesia. One of them is in the city of Surabaya.

The systematic review and meta-analysis of Hwang et al. In 2014, the 118G allele frequency in Asia included Korea, Singapore, and China which accounted for 38.8\%, 39.2\% and $37.1 \%$ of the population, respectively. Meanwhile, the European population, namely Italy and Pennsylvania, were $18.4 \%$ and $14.0 \%$, respectively. It is seen that the prevalence of SNPs for this gene is generally found to be high in Asian populations.

In contrast to South Asian countries, including Pakistan and India, the prevalence of the G allele in the A118G SNP of the OPRM1 gene tends to be lower, $14.5 \%$ and $17.8 \%$, respectively (Ahmed et al., 2018) (Kumar et al., 2012). These frequencies are more similar to the allele frequency distributions in African American and European populations, which range from $4 \%$ to $16 \%$ of the population (Schwantes-An et al., 2016). Thus, this study and the research of Puspitasari et al. (2020) shows that Indonesia, with the majority of subjects being Javanese, tends to have the highest $118 \mathrm{G}$ allele frequency (55.6$60.4 \%$ ) among Asian countries, followed by ethnic Malays (53.1\%). This also supports the theory that demographics may be a contributing factor, given that Malaysia may have the closest demographic and ethnic characteristics to Indonesia.
Differences in Genotype Frequency Distribution in SNP A118G Gene OPRM1 with Gender

Genotype distribution based on sex in this study was found in male genotypes, namely homozygous mutants (GG) of $47.5 \%$, followed by AG $30 \%$ and the lowest was AA, which was $22.5 \%$. Meanwhile, for female gender, this study found that the highest genotype frequency was GG, which was $38.75 \%$, followed by AG at $33.75 \%$ and the lowest was AA, which was $27.5 \%$.

Then it was found that there was no deviation in the prevalence of SNP A118G gene OPRM1 of this study subject with all values of HWE $(\chi 2)>0.05$ both male or female and total subjects. In this study, there was also no significant difference in the frequency distribution of the A118G SNP gene OPRM1 genotype based on the sex of the subject with $\mathrm{p}$ value $>0.05(\mathrm{p}=0.46)$

\section{Differences in Allele Frequency Distribution in SNP} A118G Gene OPRM1 Based on Gender

The distribution of allele frequencies by gender, in this study, $37.5 \%$ of the $118 \mathrm{~A}$ allele was found in males and $62.5 \%$ of the $118 \mathrm{G}$ alleles of a total of 80 alleles, while in females the $118 \mathrm{~A}$ allele was $51.2 \%$ and the $118 \mathrm{G}$ allele was $48.8 \%$. of a total of 80 alleles. Puspitasari et al. (2020) found out that $33.5 \%$ of $118 \mathrm{~A}$ alleles were obtained for men and $66.5 \%$ of $118 \mathrm{G}$ alleles from a total of 158 alleles, while in women the $118 \mathrm{~A}$ allele was $45.6 \%$ and the $118 \mathrm{G}$ allele was $54.4 \%$ of the total 158 alleles.

Based on this description, it can be concluded that this research is in line with the research of Puspitasari et al. (2020) which also found that the frequency of the G allele in men was higher than in women. Although in this study, there was no significant difference in the frequency distribution of the SNP A118G allele of the OPRM1 gene based on the sex of the subject with a $\mathrm{p}$ value $>0.05(\mathrm{p}=$ 0.08 ), while Puspitasari et al. getting male sex has a higher $\mathrm{G}$ allele frequency distribution with a $\mathrm{P}$ value $<0.05(\mathrm{p}=$ 0.029).

Through this, it can be seen that the Indonesian population requires high doses of opioid analgesics. In addition, the average male gender has a tendency to require higher doses than women.

\section{CONCLUSION}

Therefore, it can be concluded that the frequency of SNP A118G of the OPRM1 gene was found to be high in the Indonesian population and had a high tendency in the male population, although it was not statistically significant.

\section{REFERENCES}

[1] Ahmed, M., ul Haq, I., Faisal, M., Waseem, D., \& Taqi, M. M. (2018). Implication of OPRM1 A118G polymorphism in opioids addicts in Pakistan: in vitro and in silico analysis. Journal of Molecular Neuroscience, 65(4), 472-479.

[2] Boules, M. L., Botros, S. K. A., Shaheen, I. A., \& Hamed, M. A. (2015). Association of $\mu$-opioid receptor gene polymorphism (A118G) with variations in fentanyl analgesia consumption after total abdominal hysterectomy in female Egyptian patients. Comparative Clinical Pathology, 24(2), 241-246.

[3] Chou, W.-Y., \& Hsu, C.-J. (2021). A118G polymorphism of OPRM1 gene caused different morphine consumption in female patients after total knee replacement. Journal of Orthopaedic Science, 26(4), 629-635. 
[4] Hwang, D. H., Kim, J.-A., \& Lee, J. Y. (2016). Mechanisms for the activation of Toll-like receptor $2 / 4$ by saturated fatty acids and inhibition by docosahexaenoic acid. European Journal of Pharmacology, 785, 24-35.

[5] Ikeda, K., Ide, S., Han, W., Hayashida, M., Uhl, G. R., \& Sora, I. (2005). How individual sensitivity to opiates can be predicted by gene analyses. Trends in Pharmacological Sciences, 26(6), 311-317.

[6] Kasai, S., \& Ikeda, K. (2011). Pharmacogenomics of the human $\mu$-opioid receptor. Pharmacogenomics, 12(9), 1305-1320.

[7] Kumar, D., Chakraborty, J., \& Das, S. (2012). Epistatic effects between variants of kappa-opioid receptor gene and A118G of mu-opioid receptor gene increase susceptibility to addiction in Indian population. Progress in Neuro-Psychopharmacology and Biological Psychiatry, 36(2), 225-230.

[8] López Soto, E. J., Agosti, F., Catanesi, C. I., \& Raingo, J. (2013). Impact of A118G polymorphism on the mu opioid receptor function in pain.
[9] Pasternak, G. W., \& Pan, Y.-X. (2013). Mu opioids and their receptors: evolution of a concept. Pharmacological Reviews, 65(4), 1257-1317.

[10] Puspitasari, A. A., Ikawati, Z., Swasthikawati, S., \& Rahmawati, A. (2020). High Frequency of the Opioid Receptor $\mu-1$ (OPRM1) A118G Polymorphism, an Opioid Drug Therapy Related Gene, in the Indonesian Population. Current Pharmacogenomics and Personalized Medicine (Formerly Current Pharmacogenomics), 17(1), 64-69.

[11] Schwantes-An, T.-H., Zhang, J., Chen, L.-S., Hartz, S. M., Culverhouse, R. C., Chen, X., Coon, H., Frank, J., Kamens, H. M., \& Konte, B. (2016). Association of the OPRM1 variant rs1799971 (A118G) with nonspecific liability to substance dependence in a collaborative de novo meta-analysis of Europeanancestry cohorts. Behavior Genetics, 46(2), 151-169.

[12] Taqi, M. M., Faisal, M., \& Zaman, H. (2019). OPRM1 A118G polymorphisms and its role in opioid addiction: implication on severity and treatment approaches. Pharmacogenomics and Personalized Medicine, 12, 361.

[13] Udayakumar, P., \& Udayakumar, S. (2021). Fentanylinduced respiratory depression: A narrative review on the possible single-nucleotide polymorphism. Anesthesia: Essays and Researches, 15(1), 4. 